\title{
Circo Teatro Biriba - Uma experiência sob a lona
}

\author{
MICHELLE SILVEIRA DA SILVA
}

Michelle Silveira da Silva é graduada em Interpretação e Direção Teatral pela UFSM e trabalha como Palhaça desde 2001. Participou de grupos de pesquisa em clown; de criação, direção e atuação em espetáculos; de oficinas com mestres da Palhaçaria; teve vivência circense, atuando no palco do Circo Teatro Biriba durante 7 meses; apresentou-se em Festivais de Palhaços e Palhaças no Brasil, conduziu Oficinas de Iniciação de Palhaços em várias cidades do país, e é organizadora da revista Palhaçaria Feminina. 


\section{- RESUMO}

O artigo apresenta a experiência artística vivenciada no Circo Teatro Biriba pela atriz Michelle Silveira da Silva, no período de novembro de 2008 a maio de 2009. Durante estes sete meses, muitas foram as formas de aprendizado da arte circense: atuando como atriz cômica e encenando personagens caricatas; organizando elementos cênicos, cenários e figurinos; auxiliando na divulgação dos espetáculos e aprendendo a partir do contato e convivência com o palhaço Biriba. As mudanças de praças, montagem da lona do circo e ensaios de espetáculo foram momentos que marcaram este processo e que contribuíram para estabelecer um diálogo entre a teoria e a prática apreendida no circo.

\section{- PALAVRAS-CHAVE}

Circo-Teatro, palhaço Biriba.

\section{- RESUMEN}

El artículo presenta la experiencia artística vivida en Circo Teatro Biriba por la actriz Michelle Silveira da Silva, desde noviembre de 2008 hasta mayo de 2009. Durante estos siete meses, hasido muchas las formas de aprendizaje de las artes circenses: actuar como una actriz cómica y puesta en escena de personajes caricaturizados, organizar los elementos escénicos, decorados y el vestuario, la asistencia en la difusión y ponerse en contacto con el aprendizaje y la vida del payaso Biriba. Cambios en las ciudades, el montaje de la carpa del circo, los espectáculos de prueba, fueron momentos decisivos en el proceso, lo que contribuye al diálogo entre la teoría y la práctica aprehendido en el circo.

- PALABRAS-CLAVE

Circo Teatro, payaso Biriba.

Sobrevive no riso circense um traço ritualístico, uma espécie de ponto de ligação entre o fim e o recomeço, entre o morrer e o renascer do homem e da vida.

Mário Fernando Bolognesi

\section{Introdução}

A vivência de sete meses como integrante do elenco da Companhia Teatro Biriba me proporcionou momentos de grande encantamento e preocupações. Encantamento no que se referia a realização de um sonho de infância, que tinha em relação à minha projeção, ou seja, o que eu imaginava que deveria ser a vida num circo. $\mathrm{E}$ preocupações no que dizia respeito à estrutura do teatro e sua funcionalidade. Pois todos os assuntos que dizem respeito ao teatro e ao espetáculo como um todo, desde sua montagem, seus ensaios, até sua apresentação, dizem respeito, ou deveriam dizer, a todos os integrantes da companhia, exigindo de todos muito envolvimento.

Conheci o Teatro Biriba no início de 2008, quando a Companhia fez temporada na cidade de Chapecó, SC. Eu nunca havia entrado em um Circo Teatro e meu conhecimento do assunto fora através de leituras e estudos. Conforme fui assistindo os espetáculos, fui entendendo a linguagem e me identificando com a figura doce e travessa do Palhaço Biriba. Pude perceber o quanto esta linguagem causa um fascínio tão grande sob o espectador, fazendo com que este retorne diversas vezes ao circo 
para acompanhar a história do Palhaço, como se fosse uma série de TV, através do envolvimento com os personagens, identificação, mas, neste caso, ao vivo.

Durante esta temporada em Chapecó, assisti com frequência aos espetáculos, participei de algumas peças como figurante e aos poucos fui me envolvendo com a linguagem e com a companhia. No segundo semestre de 2008, manifestei a Geraldo Passos, dono do circo, meu interesse em integrar o grupo, contribuir com este e em troca aprender com eles, o que certamente não se aprende em uma academia.

No início de novembro realizei minha mudança para o circo, na ocasião instalado na cidade de Xanxerê, SC. O circo no qual eu ingressei estava passando por uma situação muito delicada, e isso certamente influenciou muito a minha percepção do lugar.

Minhas primeiras impressões foram aos poucos se modificando conforme eu ia me envolvendo com as questões do circo, e estas eu fui registrando em uma espécie de "diário do circo", onde anotava também meus questionamentos, experiências e textos e que aqui servirão para descrever esta aventura.

a entrada triunfal do palhaço, suas graças do início ao fim do espetáculo enchendo o coração da gente de inocência, a alma de alegria e o rosto de risadas, toda esta emoção sentida enquanto público e apreciador do teatro é trocada por outras tantas quando se deixa de ser encantado para se ser parte encantadora. Agora consigo ver por detrás das cortinas, nos bastidores todo o trabalho árduo que é empregado pelos artistas, a fim de que para o público a ida ao teatro seja sempre uma festa. Desde a desmontagem do teatro de uma cidade, a viagem, a montagem da lona em outra cidade, a preparação para a estreia, a produção, os ensaios, todo o envolvimento dos artistas para que o espetáculo aconteça, a rotina, o cotidiano, questões de ordem pessoal, do convívio, questões financeiras, pensamento e questionamentos artísticos, as dificuldades, o preconceito, a recepção, o calor humano do público, o retorno, tudo isso adquire outra dimensão nunca antes vislumbrada (Diário do Circo - fevereiro de 2009 - Naviraí, MS).

Viver num circo pede que se tenha muito desprendimento, tem que se abrir mão de muitos interesses em razão de outro, a própria vida no circo. Neste artigo, pretendo falar do que mais me chamou a atenção na estrutura circense e na sua rotina diária, desde as mudanças de cidade, a montagem da lona, os ensaios das peças, a relação com os artistas da companhia e a experiência única de se fazer circo-teatro.

\section{Circo ou teatro?}

A Companhia Teatro Biriba é uma companhia teatral que há 40 anos viaja pelo interior do Estado de Santa Catarina, aventurando-se em algumas cidades do Paraná e Mato Grosso do Sul, com uma estrutura móvel que se desmonta e monta em cada nova cidade; esta estrutura caracteriza-o como um teatro de lona. O Teatro Biriba surgiu no ano de 1970, com sua estreia na cidade de Tangará da Serra, no interior de SC, sob a direção de Geraldo Passos, o Palhaço Biriba. Com seu falecimento no ano de 1991, a Companhia fica aos cuidados dos filhos e da esposa. No ano de 2004, a Companhia se divide em duas: uma parte passa a ser administrada por Geraldo Santos Passos, o palhaço Biriba, filho de Geraldo Passos, e a outra por Cida Passos (irmã dele), com o Palhaço Biribinha, Adriano Passos, neto de Geraldo. Esta última companhia, itinera pelo RS e litoral catarinense, enquanto a outra se dedica à região 
central e oeste do estado de Santa Catarina.

O que se realizava e continua se realizando debaixo desta lona são apresentações de teatro. Uma linguagem muito específica de atuação e de construção dramatúrgica dá a esta linguagem o nome de Circo-Teatro. Não se trata de um espetáculo de circo, com show de variedades e artistas como malabaristas, mágicos e acrobatas, apesar de ser realizado sob uma lona circense e de ter como figura central o palhaço. É teatro, mas um teatro que não recorre aos clássicos da dramaturgia universal como Shakespeare, Moliére, nem mesmo textos do Moderno Teatro Brasileiro como Nelson Rodrigues. Tão pouco tem caráter experimental ou se deixa influenciar pelas tendências da dramaturgia e atuação contemporâneas. As peças que são apresentadas num circo-teatro são dramas, melodramas e comédias. As comédias, em sua maioria, são escritas de forma que a trama se desenrole, tendo como figura central o Palhaço, aproximando-se muito da Commedia Dell 'Arte, tanto na estrutura dramatúrgica, recursos cômicos, tipos cômicos, improviso, entre outros.

Cada um dos gêneros segue uma estrutura dramática, temática e personagens recorrentes, ou seja, que estão sempre presentes na cena. As comédias também assemelham-se a uma série de televisão, que você assiste diariamente para saber quais as novas aventuras do personagem, ou herói, neste caso, o palhaço. Logo, a estrutura física externa é de um circo, a estrutura interna é de um teatro e a linguagem que se encena é a do circo-teatro.

Neste contexto, a palavra circo é empregada para definir o espaço físico e a relação imaterial que estabeleci com este espaço. A questão estrutural da lona, trailers, propagandas, músicas, brilhos, pipocas e maçãs do amor (que habitualmente não se come no teatro) e principalmente a figura do palhaço, atuam em nossa subjetividade. Envolvidos nesta atmosfera, somos conduzidos a pensar: tudo aqui nos dá indícios de que isso é um circo, no entanto, o que se faz aqui é teatro. Mas no momento em que o palhaço toma conta da cena, a palavra teatro fica em segundo plano. Assimilamos a informação, mas nosso imaginário registra que fomos ao circo.

\section{A chegada de uma novata no circo-teatro}

Inicialmente, fazer parte de uma companhia de Circo-Teatro, que viaja pelo país com uma lona a ser montada e desmontada a cada cidade, e que leva consigo um palhaço que se apresenta diariamente, para mim, já era grande parte da realização de um sonho de infância, e ao mesmo tempo uma oportunidade única de estar pesquisando na prática tudo o que eu, há alguns anos, vinha estudando na teoria. Livros e experiências alheias já não me bastavam na continuação da minha pesquisa, que tem sido constante desde o ano de 2001, quando comecei a trabalhar com a linguagem circense, mais especificamente a do palhaço e de todos os seus desdobramentos.

Era chegada a oportunidade e o momento: não de menosprezar os autores que por tanto tempo me serviram como referência e despertaram em mim o interesse pela arte circense, mas chegou o tempo de colocar em prática essas teorias.

Envolvida pela fantasia e pelo encantamento que me impulsionaram a viver essa "aventura", utilizei como forma de registrar essa experiência o meu "diário do circo" e minha máquina fotográfica.

Segue-se o relato da minha chegada ao circo e de como fui conduzida e recepcionada. 
A sandália era bege de couro trançado. Enquanto viajávamos, Geraldo teve o cuidado e a sensibilidade de preencher o vazio da minha partida com assuntos de ordem de trabalho, de artista, de humano, de mestre. Todas as palavras e conselhos me mantiveram atenta, curiosa, e não menos encantada, pois ali se iniciava o meu rito de iniciação ao circo e eu estava sentada ao lado do meu mestre Biriba e sua voz me soava tal qual melodia que toca e engrandece a alma. Geraldo me conduzia como quem trouxesse para casa uma caça desejada, um ente querido, um prêmio, um presente, uma promessa. Pareceu-me que estava muito feliz com esta aquisição para o seu circo. Ao desembarcarmos da velha camionete, fui recepcionada pela esposa de Geraldo, Leila Passos, que em meio a um abraço carinhoso, proferiu a seguinte saudação: Seja bem- vinda! E mais uma vez fui tomada de emoção, e ela percebeu (Diário do Circo, novembro de 2008, Xanxerê, SC).

Nesses primeiros dias, foram se apresentando para mim, histórias e cenas de um cotidiano completamente diferente do meu, mas que já me davam lições de humanidade e de sociedade.

Viver num circo é viver numa sociedade, num bando, como herança de ciganos, num grupo de pessoas que moram juntas, cujos poucos metros separam uma moradia da outra, e a convivência é diária e intensa, tanto no trabalho como no lazer e no cotidiano. A vida, a arte e o ofício se cruzam e se misturam.

Em minhas primeiras semanas no circo atuei como cozinheira em uma cozinha coletiva e como "babá", ajudando a cuidar das filhas de uma atriz da companhia que havia sofrido um acidente há dois meses. Relato na sequência o meu primeiro contato com ela.

No trailer ao lado da cozinha e em frente ao meu quarto, mora um jovem casal, artistas da companhia e duas lindas meninas. A mãe a pouco sofreu um grave acidente que segundo ela, Ihe destruiu e fez com que suas forças sumissem, fugissem, não sabe ela pra onde. Eu estava sentada na frente da cozinha quando ela, com certa dificuldade para falar, me perguntou se eu sabia fazer penteados. Respondi que sim. Ela pediu ao marido que trouxesse o pente e os grampos de cabelo. Subi alegre a escadaria da frente de seu trailer e comecei a pentear seus cabelos. Elogiei-os porque são realmente bonitos. Estava muito quente. O calor era prenúncio de chuva. A atitude dela, foi bonita, foi uma tentativa de aproximação. Foi um convite pra fazer parte da sua vida (Diário do Circo, novembro de 2008, Xanxerê, SC).

Acreditei que a convivência com as pessoas do circo fosse um pouco difícil. Inicialmente, alguns fatos que pude perceber, e julgo que contribuíram para isso, foi o fato de eu não ser de tradição circense; este foi o primeiro ponto que imperou. Logo, parecia um pouco perdida dentro desta nova realidade que me foi apresentada, tão diferente do meu cotidiano, e assim, acabei despertando a desconfiança de algumas pessoas pelo fato de me faltar experiência de circo-teatro.

Quando dizemos que temos Faculdade em Teatro, isso geralmente causa outro choque, uma espécie de repulsa ao nosso aprendizado que, na verdade, nada mais é do que própria defesa.

É como se fôssemos chegar à Companhia, e com um pensamento acadêmico pudéssemos ditar regras e conceitos que invalidam anos de atuação e vivência de 
um teatro popular.

É muito importante que eu diga que esta atitude deu-se por parte de algumas pessoas e durante um tempo, ou seja, a partir do momento que demonstrei através de atos concretos que a minha estada no circo era para trocar conhecimento com as pessoas, aprender com o conhecimento delas e me lançar nesta pesquisa prática, sem preconceitos e julgamentos, neste momento todas as resistências se desfizeram, principalmente quando me viam trabalhando no pesado sem reclamar e com entusiasmo: esta foi a maior prova de aceitação, e é como se fosse mesmo um ritual de iniciação.

Conquistada a confiança, e depois de ter passado pela "prova de fogo" do palco, passei a fazer parte do grupo efetivamente.

\section{As mudanças de "praça"1}

Depois da recepção e convívio, a minha segunda experiência marcante foi a mudança de uma cidade para outra.

As mudanças saem da cidade, geralmente de madrugada, para que os caminhoneiros possam aproveitar o tempo de viagem. E enquanto não estão todos os trailers e carretas na nova praça, Geraldo, o palhaço Biriba, não descansa. É uma viagem atrás da outra, geralmente com 15 horas, dormindo na estrada, tomando banho em posto de gasolina e ligando raramente para dar notícias.

O período de espera aos que levam as cargas deixa o espaço do circo vazio e quase sem ação. Ficávamos esperando o retorno dos caminhões para sabermos qual carreta iria na próxima viagem e assim organizávamos rapidamente o que faltava, pois os objetos maiores já estavam preparados para a viagem. As carretas ficavam de pré - aviso, logo eram desfeitas as instalações elétricas e de água a fim de agilizar a saída da carga.

Chegando à cidade, o secretário de circo tem que viabilizar a ligação de luz e água, caso isso não tenha sido providenciado ainda, geralmente pelas dificuldades burocráticas que são impostas aos circos. Nesse processo, o secretário do circo desempenha um papel muito importante: ele viabiliza toda a burocracia necessária para a instalação do circo na cidade. E quando chegamos, a luz já deve estar instalada e a água também.

Esse processo de mudança é muito desgastante para todos os artistas do circo. No caso do Teatro Biriba, é sempre ele, o palhaço Biriba, e um dos atores que tenha experiência em guiar uma carreta, que fazem o transporte das cargas. No tempo em que estive lá, seus ajudantes nesta função foram Pedro Moreno (ator) e, no transporte dos trailers, Walério Silveira (o escada² do Palhaço e galã da companhia). Sempre são muitos dias na estrada, onde se deve ter uma atenção redobrada, pois as cargas são muito grandes, e os gastos nesse período também são volumosos, porque além

Praça, na linguagem circense, se refere a outra cidade onde a estrutura do circo será instalada. É comum os donos do circo, ou mesmo o secretário de circo, dizerem que estão indo fazer praça, ou seja, estão indo até a cidade em que desejam se instalar na seqüência para preparar o terreno, solicitar instalação de água e luz, vistoria de bombeiros, da vigilância sanitária e até do conselho tutelar, além de iniciar a divulgação da nova temporada contatando rádios, jornais, televisão e comércio local.

2 É considerado "Escada" no circo - teatro, assim como também nos circos tradicionais brasileiros, o personagem que faz dupla com o palhaço e prepara suas piadas, servindo como trampolim para o palhaço. Associa-se a figura do escada ao Branco, da clássica dupla cômica Branco e Augusto, onde o Branco representa a ordem, a inteligência, a sabedoria que é quebrada pela doce estupidez do Augusto. 
de combustível, tem que se investir em alimentação e manutenção das cargas, isto é, pneu e alguma peça que estrague neste trajeto.

No circo ficam as mulheres, as crianças e os idosos responsáveis pela organização e limpeza do espaço e por articular o que será realizado na chegada na nova cidade.

Esse processo de mudança pode durar até 20 dias, dependendo das condições financeiras e humanas para transportar as cargas, assim como varia de acordo com a distância entre uma cidade e outra.

No período em que estive na Companhia Teatro Biriba, realizamos quatro mudanças de praça: Xanxerê (SC), Chapecó (SC), Guaíra (PR), Naviraí (MS) e Maravilha (SC).

Segue um relato sobre a mudança da cidade de Chapecó (SC) para Guaíra (PR):

As carretas do circo demoraram a sair do terreno de Chapecó por falta de dinheiro e nada mais. A praça ruim, dinheiro de menos depois de um triste acidente que desestruturou o Teatro Biriba e que ao mesmo tempo deu início a uma nova etapa da história deste Circo Teatro. A mudança deu-se na questão estrutural, administrativa e artística. Mudou-se o pensamento em relação ao tipo de artista com o qual se deseja trabalhar. [...] Saímos de Chapecó em direção a Guairá, divisa entre Paraná e Mato Grosso do Sul e divisa com o Paraguai. Aproximadamente umas 15 horas de viagem. Dona Suzi e eu chegamos à tardinha e ficamos hospedadas num hotel simples, mas agradável. A felicidade do Régis em nos ver foi tão bonita, coitado, estava se sentindo abandonado, só via carreta chegando e caminhão saindo. Diga-se de passagem, que os grandes heróis desta mudança foram o Geraldo, o Pedro e Walério que fizeram infinitas viagens para trazerem as carretas e os trailers para cá (Diário do Circo, fevereiro de 2009, Guairá, PR).

Neste processo de mudança de praça, o ator Régis D'Avila teve grande função, a de cuidar os trailers enquanto a lona ainda não havia sido instalada. Régis foi integrante da Companhia Teatro Biriba durante dois meses, atuando como ator, contrarregra e desempenhando demais funções dentro do circo. Graduado em Direção Teatral pela Universidade Federal de Santa Maria no RS, a título de curiosidade, ingressamos juntos no curso de Artes Cênicas, e partiu de mim o convite para que ele viesse fazer parte da Companhia. E foi ele quem, mesmo indiretamente, me fez levantar vários questionamentos a cerca da minha permanência no teatro. Estes questionamentos se referiam à convivência e à própria profissão e profissionalismo, onde entrarão minhas questões ideológicas, idealistas a respeito da ética para com o trabalho. Na questão da convivência, o Régis me ajudou muito a sustentar o tempo no circo. Teve um dia que ele ficou muito mexido com a experiência que estava vivendo na mudança de praça e montagem da lona, e que consequentemente mexeu comigo também.

Os homens do teatro trabalharam arduamente na montagem das torres do teatro, de baixo de sol, de calor, de garoa, de mormaço. No almoço, o Régis comentou que está muito cansado deste trabalho braçal, o que realmente é muito pesado para os homens do teatro, bendito machismo que impera por aqui. E disse também que se sentiu mexido quando o capataz Pedro, se referiu a marreta de bater estacas como, 'a caneta de quem não estudou', mas o Régis estudou bastante e chega a pensar que está no lugar errado (Diário do Circo, fevereiro de 2009, Guairá, PR). 
Passado o momento de mudança de cidade, é chegado a hora da instalação na nova praça, é o momento de organizar o espaço onde se vai viver e trabalhar durante os próximos meses.

\section{A montagem da lona}

Quando o circo chega à cidade, o que se faz primeiro é distribuir as moradias ao redor de onde será montada a lona, de forma a se desenhar um grande círculo. Próximo a entrada do circo, geralmente fica a moradia dos donos do circo, a frente do circo, sempre voltada para o lugar que melhor se avista e que dá mais acesso ao público.

Organizadas as moradias e instaladas as famílias, começa-se a montagem da Iona envolta de muito misticismo e trabalho árduo por parte dos homens da Companhia aliada às figuras dos "peludos"3.

Dependendo da quantidade de mão de obra capacitada para a montagem do circo ela pode durar de dois a quinze dias, aproximadamente.

A montagem da lona estava cada vez mais se enrolando e os homens aqui do Teatro não têm condições de montá-la sem a presença e o encaminhamento de alguém entendido do assunto, neste caso, um capataz de circo, aquele que comanda, dá as ordens e é capaz de levantar a lona do circo em um dia. Este homem abençoado chegou no circo ontem à noite, Pedro, pedra. Mal desembarcou do carro depois de uma viagem longa, e já estava a medir o terreno onde seria montada a lona no dia seguinte. As $6 \mathrm{~h}$ e 30 min do dia seguinte ele já estava no terreno do circo, batendo estacas e demarcando o território. Acordei com as badaladas da marreta (Diário do Circo, fevereiro de 2009, Guairá, PR).

O primeiro procedimento para a montagem da lona é medir o terreno e demarcar os espaços onde ficará a lona do circo e onde ficará a lona menor da entrada e da praça da alimentação, chamada no circo de marquise.

A distribuição espacial em formato circular que assume a montagem do circo traz em si significados que podem ir além de uma demarcação de território e de proteção à lona, parece-me que encerra em si um misticismo que se refere a círculo, roda, ciclo, ritual. Nesta perspectiva, Jean Pierre Angrémy, ao escrever o prefácio do livro "O circo no risco da arte", diz:

O círculo do circo, por sua perfeição particular, oferece um objeto de estudo complexo e admirável. Existe nesse círculo traçado no solo tal qual um esquema xamânico, um espaço fora do lugar, de uma isenção mágica, no qual se entra apenas na condição de iniciado. É sem dúvida o charme da forma antiga do circo na qual se convoca toda a cidade, o grande público para assistir aos desafios, as performances, as dívidas da comunidade aos ritos e às tradições secretas e excessivamente protegidas e de fazer das performances dos iniciados um espetáculo público (WALLON, 2009, p. 7).

\footnotetext{
3 Peludos: assim são chamados os rapazes da cidade que são contratados para auxiliar na montagem da lona do circo. Geralmente pessoas muito humildes das comunidades, entre eles alguns bêbados e de índoles duvidosas. Mas o que se espera deles, quando são contratados, é que auxiliem o capataz do circo, aquele que sabe como montar o circo e dá as ordens. As mulheres do circo são aconselhadas para que não conversem com os "peludos" nada além do necessário, uma convivência educada, geralmente nos momentos em que estas lhes servem o lanche. Este procedimento visa evitar possíveis envolvimentos com pessoas das quais não se sabe nada.
} 
Neste espaço circular demarcado para a montagem da lona, mulher nenhuma pode cruzar enquanto os homens estiverem trabalhando. As mulheres precisam fazer a volta no terreno, um círculo maior ainda, seja dia, seja noite, nunca se deve cortar o terreno no meio antes que a lona seja levantada, com risco de trazer má sorte para a praça. Creio que existam outras versões para este misticismo, que sempre respeitei enquanto estive na Companhia. Acredito que o mais provável seja que essa decisão por parte de antigos donos de circo tenha surgido para impedir que as mulheres da Companhia se misturassem com os "peludos", e assim distraíssem a atenção dos trabalhadores. Outro fator importante que pode ser motivo para esta decisão arbitrária é que realmente correm-se riscos durante a montagem da lona. Os homens manipulam estruturas de ferro muito pesadas que, se caírem, podem machucar e até matar. Então esta medida também tem por objetivo proteger as mulheres e crianças

A montagem da lona não deixa de se assemelhar a um ritual. O ritual da preparação do espaço sagrado onde irá desempenhar o ofício, e para isso, e nesse caso, é preciso que a força seja doada para esta edificação.

$\mathrm{Na}$ sequência, levantam-se as torres de ferro ou mastros, dependendo da estrutura que o circo dispõe. Abre-se a lona no chão, dividida em quatro partes sob pedaços de lona velha para que não suje a que será erguida. As lonas são muito pesadas e precisam de muita força para serem transportadas, abertas e preparadas para serem erguidas. No Teatro Biriba, a lona é levantada com a ajuda de uma maquinaria com roldanas, o que facilita a mão de obra. A partir da base de quatro torres de ferro, em cada uma, um homem manipula a manivela que dá funcionalidade a roldana, e assim a lona é erguida.

Depois da lona montada, começam os preparativos para a grande estreia na cidade nova. Montagem de palco, de plateia, lavagem das cadeiras, colocação das cadeiras, revestimento do palco, preparação e limpeza da lona de entrada, instalações elétricas no circo e tudo que diga respeito à estruturação física do espaço. Se não bastasse toda a correria do dia de estreia, os atores ainda pensam em seus papéis que serão executados à noite.

Para os iniciantes como eu, que havia chegado a pouco no circo, esse dia era muito preocupante, tinha-se que deixar todo o espaço organizado uma hora antes do espetáculo começar a caracterização, porque o texto já tinha que estar decorado.

\section{A experiência na cena - os ensaios e o palco}

O teatro feito na Companhia do Teatro Biriba, assim como acredito ser em várias outras companhias de Circo-Teatro, é abordado de forma completamente diferente da que eu estava acostumada a trabalhar.

Vinha de uma experiência universitária, onde era comum se ter um diretor que escolhe um texto e encaminha a criação dos atores para a montagem da obra de acordo com sua própria concepção. Ou, cria-se em conjunto, o que se chama de criação coletiva, onde todos os integrantes na criação livre ou conduzida vão delineando a estrutura do espetáculo. E este processo dura geralmente um ano de pesquisa e estudo do texto e também das ações do ator na cena.

Chegando ao Teatro Biriba, a realidade era completamente diferente. Lembro-me que a primeira pergunta que me fizeram foi: "- Como você decora o texto? Bem, eu decoro o texto juntamente com a ação, e com o entendimento do texto aliado à 
ação." Será? Eu mesma comecei a me questionar: Como eu decoro um texto?

Leila Passos, a esposa de Geraldo Santos Passos, o palhaço Biriba, me ensinou como eles fazem para decorar os textos. Pegam um caderno e copiam do texto original as falas do seu personagem e as deixas, ou seja, as últimas palavras dos outros personagens com os quais está em cena. E assim fiz, não tendo muita certeza de que isso iria funcionar.

Minha primeira personagem teve uma participação pequena na cena: era uma empregada doméstica e Biriba me passou as informações de que ela era prestativa e esperta. Segundo ele, esta era a linha da personagem, e assim o fiz. Tivemos um ensaio.

Essa situação para mim foi um pouco assustadora no início, saber que subiríamos ao palco todas as noites com espetáculos diferentes, textos sempre diferentes, personagens diferentes e com um ensaio apenas. Isso é de assustar qualquer pessoa.

Segue o relato de minha primeira experiência no palco do Teatro Biriba.

Estudei a 'Carola' há dias, minha preocupação foi decorar o texto. Hoje, às 14hs, ensaiei com o Geraldo no palco e ele me deu instruções sobre entradas e saídas de cena e de cara já percebeu que sou muito ansiosa e vou engolindo o final das frases. Até a hora da minha estreia fiquei estudando o texto e pensando nas frases. Antes de entrar em cena e dizer meu primeiro texto: "Com licença patrão. Tem um senhor aí fora que deseja falar com o senhor. Diz ser seu amigo, Biriba Aparício.", Geraldo colocou a mão no meu ombro e disse para eu ficar calma que ele iria me dar o sinal para eu entrar em cena, e no momento ele disse: 'Vai'. Este ato foi muito generoso da parte dele, e me passou segurança naquele momento (Diário do Circo, janeiro de 2009, Chapecó, SC).

O meu terceiro personagem e o mais significativo foi a Terezinha de Biriba no Espeto, outra empregada doméstica, no entanto, com personalidade muito forte e, além disso, era a namorada do Biriba, ou seja, estava em cena grande parte do tempo e atuava em suas cenas como sua partner. Isso era o mais difícil de assimilar. Qualquer erro poderia comprometer a atuação do palhaço, o que me deixou sob pressão.

$\mathrm{Na}$ hora da apresentação, eu sempre deixava o meu caderno nos bastidores e lia sempre as falas antes de entrar em cena, pois além delas eu tinha que aliar a movimentação cênica marcada, porque, muitas vezes, o desfecho dava-se pelas saídas do palco. No caso desta peça, no encerramento do primeiro ato, Biriba pede um beijo à Terezinha que se nega a dá-lo antes do casamento. Ele insiste e corre atrás da empregada: neste momento, ela tem que sair pela porta do fundo, por onde entrará o Poeta, e o Biriba vai beijá-lo como se fosse beijar a namorada. Neste dia, sabendo da marcação, resolvi mudar meu trajeto sem dar explicações, dei uma volta a mais antes de sair, o poeta entrou antes, e o desfecho do ato não aconteceu.

A esta apresentação seguiram-se várias da mesma peça e de outras tantas em que me desafiei na cena, com personagens geralmente caricatas ou empregadas. Os papéis são distribuídos de acordo com o tipo físico dos atores, o que acaba delineando seus personagens.

Sobre as personagens caricatas, Ernani de Almeida diz: "Esta é uma dama de idade, esposa do 'baixo-cômico': ela faz confusões, entende de uma maneira e não é aquilo. É uma mulher austera, moralista e braba" (MAGNANI, 1984, p. 93). Desem- 
penhei esses papéis nas seguintes peças: "Os três gostosões"; "Biriba candidato a prefeito e Biriba", "o Falso Conde".

Com o tempo, estar em cena se tornou cada vez mais fácil e prazeroso para mim. Porque fui percebendo que o segredo, se é que existe um ou vários, estava em compreender a linguagem do teatro que fazíamos todas as noites. Uma linguagem popular, e na qual, como me disse Dona Suzi, quando cheguei ao circo, tem que se ter naturalidade na cena. Então, toda a minha experiência com o jogo e com a improvisação em cena, vinda do meu trabalho de palhaça, tinham que ter alguma funcionalidade dentro daquela estrutura. O espaço de jogo é pequeno, quem joga é o palhaço e seu partner, os outros personagens desempenham suas funções exatas para ajudar o palhaço. Todos os personagens existem para fazer a graça do palhaço.

A respeito desta relação entre palhaço e partner dentro da estrutura da comédia de circo-teatro, Magnani diz:

O que caracteriza a chanchada, entretanto, é a improvisação dos atores, principalmente da dupla palhaço e clown: a história, na maioria das vezes, é mero pretexto ou pano de fundo para as mais disparatadas situações, que acabam diluindo ou colocando em segundo plano o enredo, quando existe. Ao contrário do que ocorre no drama, a ação e as demais personagens, neste caso, giram em torno do cômico, na realidade o elemento estruturante da representação. Vale a pena, contudo, descrever a estrutura mínima que sustenta a narrativa das peças, pois é o que abre e delimita o espaço da improvisação e criatividade (MAGNANI, 1984, p. 96).

O mais difícil de aceitar na cena foi ter que negar por algum tempo o que eu sempre acreditei no teatro, na construção e elaboração de um personagem e na complexidade de suas ações. No Teatro Biriba, é como se tivéssemos que adquirir um equipamento que de um dia para o outro nos entregasse o personagem pronto. A este equipamento dou um nome: desprendimento ${ }^{4}$.

\section{A partida}

Permaneci na Companhia de novembro de 2008 a maio de 2009; nos últimos meses, dividia minha semana entre o Teatro Biriba e meu novo trabalho na Prefeitura Municipal de Chapecó. Foram sete meses de trabalho muito intenso, onde pude atuar em diferentes funções dentro do grupo, experimentar situações diversas, até tomar a decisão de que era o momento de partir.

Disponibilizar-me as funções do Circo-Teatro foi muito valioso para mim, em âmbito pessoal e profissional. Atuei como coadjuvante, "escada" do palhaço, ponto, auxiliar de cenografia, camareira, auxiliar de divulgação, bilheteira, faxineira e palhaça nos finais de semana.

No entanto, chegou um determinado momento em que as questões financeiras e a instabilidade, decorrentes da característica nômade de uma lona de circo, começaram a pesar mais para mim.

Depois de uma grande empreitada lavando com esponja a lona do circo, anun-

\footnotetext{
4 Desprendimento: ato de desprender, de soltar. Desprender: soltar, desatar. É preciso soltar e desapegar das idéias pré-estabelecidas e se abrir para o novo e rico conhecimento que se pode adquirir. 
ciei a minha partida. Num primeiro momento, a maioria dos colegas não aceitaram a minha saída, mas uma palhaça certamente não nasceu para ficar à sombra de seu mestre, e era preciso romper a lona e alçar novos voos. E assim foi.

Geraldo parecia estar chateado comigo, desde que soube da minha saída da Companhia. Estávamos voltando de uma viagem a Curitibanos, quando Geraldo me questionou na mesa do restaurante: 'Qual é o teu sonho?' E eu não soube o que Ihe responder. Neste momento, ele foi pontual: "Você não tem mais idade pra não saber qual é o teu sonho." Levantei-me da mesa e sai em direção a mesa das sobremesas. Quando retornei à mesa, Geraldo me disse: 'Eu sei qual é o teu sonho'. Você quer que a Barrica (minha palhaça) seja reconhecida internacionalmente. E este também é o meu sonho pra você, é só por isso que eu deixo você ir embora. (Diário do circo, maio de 2009).

Lembro-me sempre desta passagem com muita emoção, pois naquele dia meu mestre demonstrou o quanto ele me admirava e me respeitava como profissional. Ter o respeito e admiração das pessoas do circo é para poucos, segundo me disse a pesquisadora de circo Verônica Tamaoki.

\section{Conclusão}

Aprendi, em curto espaço de tempo, na prática viva de atuação, que se pode viver e sobreviver de teatro, mesmo que isso signifique algumas privações.

Entendi que se pode fazer um teatro popular que tenha como objetivo diário agradar o público e colocar isso em primeiro lugar.

Compreendi que para se entender, um pouco, como funciona a realidade de um circo, ou de qualquer outro grupo social desconhecido, é preciso que se viva dentro dele e que se envolva com suas atividades de alguma forma, dedicando-se à elas intensamente.

Percebi que o Teatro Biriba, que há 40 anos desempenha seu papel na sociedade, levando o teatro às pessoas, e as pessoas ao teatro, provocando uma identificação com a plateia e contribuindo para a construção de sua subjetividade e do seu imaginário, é mais uma das significativas iniciativas de se manter viva as tradições, mas com o olhar ávido pela inovação.

Entendi que fazer circo é uma experiência muito mais complexa do que se pode imaginar, e que é uma fonte inesgotável de trabalho, de inspiração, de conhecimento e de magia.

\section{Referências}

BOLOGNESI, Mário Fernando. Palhaços. São Paulo: Editora Unesp, 2003.

MAGNANI, José Guilherme Cantor. Festa no pedaço: cultura popular e lazer na cidade. São Paulo: Editora Brasiliense, 1984.

ROCHA, Ruth. Minidicionário. São Paulo: Editora Scipione, 2003.

WALLON, Emmanuel. O circo no risco da arte. Belo Horizonte: Editora Autêntica, 2009. 